\title{
Centenaria institucionalizada recuperada por COVID-19 con generación de inmunidad: Un caso de estudio
}

\author{
A centenarian institutionalized patient who recovered from COVID-19 and developed immunity: A case study
}

\author{
José Leonel Zambrano-Urbano1,2* orcid.org/0000-0002-4959-9136 \\ Nathalia Buitrago-Gómez1,2 orcid.org/0000-0001-7466-9645 \\ Juan Felipe Muñoz-Realpe 1,2 orcid.org/0000-0002-1622-8873 \\ Jose Mauricio Ocampo-Chaparro1,2,3 orcid.org/0000-0001-6084-4764 \\ Carlos Alfonso Reyes-Ortiz ${ }^{4}$ orcid.org/0000-0001-7983-7791
}

1. Departamento de Medicina Interna, Facultad Ciencias de la Salud, Universidad Libre. Cali, Colombia.

2. $\quad$ Grupo Interinstitucional de Medicina Interna (GIMI 1), Cali, Colombia.

3. Departamento Medicina Familiar, Facultad de Salud, Universidad del Valle. Cali, Colombia.

4. Institute of Public Health, Florida A \& M University, Tallahassee, FL, USA. por COVID-19 con generación de inmunidad: Un caso de estudio. Univ. Salud. 2021;23(3):301-308. DOI: https://doi.org/10.22267/rus.212303.244

\section{Resumen}

Introducción: El virus SARS-CoV-2 y su enfermedad COVID-19, afecta con mayor severidad a personas adultas mayores, sobre todo aquellas con multimorbilidad y fragilidad; esto debido a mecanismos fisiológicos como la inmunosenescencia o un pobre control de la actividad inflamatoria en esta población. Los estudios sobre el diagnóstico y tratamiento en estos pacientes son escasos y muchos de ellos tienen niveles de evidencia bajos. Objetivo: Describir las características clínicas y paraclínicas de una adulta mayor centenaria institucionalizada, frágil, con multimorbilidad quien sobrevive a la infección y desarrolla inmunidad en una unidad geriátrica de agudos. Presentación del caso: Centenaria institucionalizada con multimorbilidad y fragilidad con criterios de severidad de la enfermedad, quien fue manejada tempranamente y recuperada, llegando a desarrollar inmunidad. Conclusiones: El diagnóstico temprano, un manejo precoz y el abordaje geriátrico integral e interdisciplinar son indispensables para un desenlace favorable en pacientes adultos mayores con alto riesgo de progresión de enfermedad con COVID-19.

Palabras clave: Infección por coronavirus; anciano; tratamiento; seroconversión; mortalidad. (Fuente: DeCS, Bireme).

\begin{abstract}
Introduction: SARS-CoV-2 virus, and the disease it causes (COVID-19), severely affects older adults (OA), especially those with multimorbidity and frailty. This is due to physiological mechanisms such as immunosenescence or poor control of inflammatory activity in this population. Studies of the diagnoses and treatments in these patients are scarce and many of them have low levels of evidence. Objective: To describe the clinical and paraclinical characteristics of a frail institutionalized centenarian female patient with multimorbidity who survived COVID-19 infection, developed immunity, and was treated in an acute geriatric unit. Case presentation: Institutionalized centenarian patient with multimorbidity and frailty who fulfilled the criteria for severe COVID-19 disease, was managed early, recovered, and eventually developed immunity. Conclusion: early diagnosis, early management and a comprehensive and interdisciplinary geriatric approach are essential for a favorable outcome in OA patients at high risk of COVID19 disease progression.
\end{abstract}

Keywords: Coronavirus infection; aged; treatment; seroconversion; mortality. (Source: DeCS, Bireme).

\footnotetext{
*Autor de correspondencia

Jose Leonel Zambrano Urbano

e-mail: jose-zambrano@unilibre.edu.co
} 


\section{Introducción}

El síndrome respiratorio agudo severo por coronavirus 2 (SARS-CoV-2) es el protagonista de la pandemia mundial actual por COVID-19 que se originó en Wuhan, China, a finales de 2019. Hasta junio de 2021 se han registrado más de 3950000 de personas muertas por COVID-19 a nivel mundial, de las que 107137 corresponden a Colombia. El 93\% del total de muertes ocurren en pacientes $>60$ años(1-6), esto explicado porque hasta un $27 \%$ de los mismos debutan con enfermedad grave al ingreso(7).

La edad es uno de los factores de riesgo más importantes para mortalidad por COVID-19(8,9). Esto es explicado por una posible eliminación ineficaz de la infección por el virus SARS-CoV-2 en el sistema respiratorio envejecido, ya que las señales de alerta viral son inicialmente lentas, lo que resulta en una mayor replicación viral y los macrófagos defectuosos, al igual que las células T con un repertorio limitado de receptores son menos efectivos, infectándose más células lo que induce altos niveles de señalización de citocinas inflamatorias, que explica la mayor tendencia hacia la tormenta de citoquinas y por ende la elevada mortalidad(10).

Durante el envejecimiento, el sistema inmunológico del adulto mayor (AM) cambia de dos formas principales, una es la disminución gradual de la función inmunológica llamada inmunosenescencia, que dificulta el reconocimiento de patógenos, la señalización de alerta y la eliminación(10), y el otro es un aumento crónico de la respuesta inflamatoria sistémica, que surge de un sistema de alerta hiperactivo, pero ineficaz; en el AM hay inmunosenescencia innata y adquirida, esta última caracterizada por atrofia tímica y acumulación de linfocitos de memoria anérgica(10,11). La atrofia tímica también contribuye a reducción de las células $\mathrm{T}$ vírgenes y acumulación de linfocitos de memoria, lo que da como resultado una inmunovigilancia

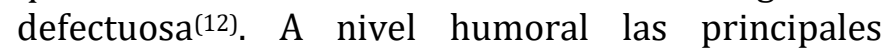
modificaciones en la inmunidad humoral presentes, son la alteración en la función de los linfocitos B a pesar que su número permanece sin cambios, una mayor respuesta policlonal frente a diversos mitógenos, y menores respuestas específicas del antígeno; de ahí que se tenga una capacidad reducida para síntesis de anticuerpos después de dicho estímulo y el defecto intrínseco en la maduración de los linfocitos $\mathrm{B}^{(13)}$.
Por otra parte, la evidencia varía en cuanto a cómo tratar a los pacientes AM que padecen COVID-19 y presentan multimorbilidad y fragilidad asociadas(14), hasta la fecha, sólo unos pocos estudios se han centrado en la experiencia de estos individuos(15). Sin embargo, se necesita más investigaciones sobre el tratamiento en esta población específica y aún más en AM frágiles centenarios, por ello, el objetivo del presente artículo es describir las características clínicas y paraclínicas de una AM centenaria institucionalizada, frágil, con multimorbilidad quien sobrevive a la infección y desarrolla inmunidad en una unidad geriátrica de pacientes agudos.

\section{Presentación de caso}

Previa obtención y firma de consentimiento informado por parte del familiar del paciente se procede a la descripción del caso clínico. Paciente de 100 años, residente de un hogar geriátrico de la ciudad de Cali, con antecedentes de hipertensión arterial (HTA), trastorno neurocognitivo mayor y glaucoma quien consultó a la Unidad Geriátrica de Agudos (UGA) por sintomatología clínica de 3 días de disnea de moderados esfuerzos, tos con expectoración hemoptoica asociada con alzas térmicas cuantificadas en $39^{\circ} \mathrm{C}$. Bajo la sospecha diagnóstica de enfermedad por COVID-19 y brote de la enfermedad en hogar geriátrico donde residía, se solicitó prueba de Reacción en Cadena de la Polimerasa en tiempo real (RT-PCR) que resultó positiva. Al examen físico de ingreso se documentó desaturación ( $\mathrm{SaO}^{2}$ 86\%), taquipneica (FR: $34 \mathrm{RPM}$ ), TA:93/53 TAM:79,67, FC:50 LPM, T:36,4, IMC:20, somnolienta, hiporexica, con necesidad de oxígeno suplementario a 5LPM por cánula nasal (Figura 1).

En paraclínicos de ingreso se evidenció linfopenia moderada, hipocalemia leve, con ferritina, proteína $\mathrm{C}$ reactiva (PCR), dímero $\mathrm{D}$ y $\mathrm{LDH}$ marcadamente elevados (Tabla 1). Se catalogó diagnóstico de enfermedad por COVID 19, escala New score 11 puntos y CALL score de 13 puntos, dentro de la clase $\mathrm{C}$ con alto riesgo de progresión de enfermedad (>50\%). 
Dentro de la clinimetría geriátrica presentaba: escala clínica de fragilidad de 8 puntos, velocidad de la marcha 0,1 m/seg, escala SPPB 1/12, escala de
Barthel de 80/100, escala de Tinetti 10/28, escala SARC-F 8 fuerza de agarre $13 \mathrm{~kg}$, Cornell 6, Pfeiffer 8 y mininutritional $23 / 30$.

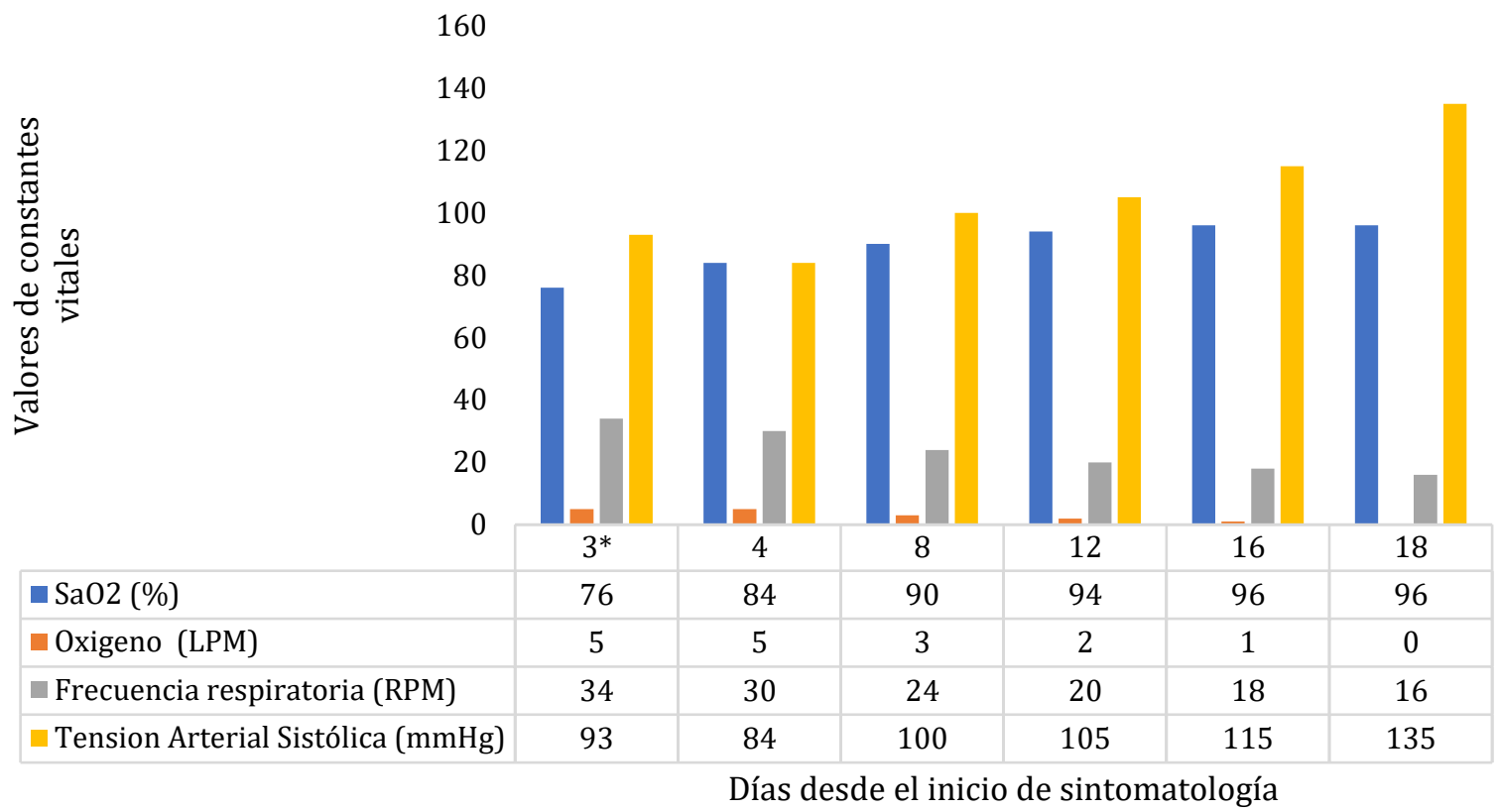

Figura 1. Evolución de principales constantes vitales de la paciente. *Día 3: administración de primera dosis ivermectina, nitazoxanida, dexametasona, ASA, atorvastatina, enoxaparina profiláctica y terapia respiratoria y ocupacional

Tabla 1. Resultados de paraclínicos y evolución de estos durante la hospitalización de la paciente

\begin{tabular}{|c|c|c|c|c|c|c|}
\hline Paraclínico & Día 3 & Día 8 & Día 12 & Día 16 & Día 18 & Valores normales \\
\hline Leucocitos & 8,5 & 10,2 & 11,2 & 12,0 & 12,0 & $4-11 \mathrm{mil} / \mathrm{mm}^{3}$ \\
\hline Neutrófilos & 7,2 & 7,7 & 8,2 & 8,5 & 8,72 & $2,5-7,5 \mathrm{mil} / \mathrm{mm}^{3}$ \\
\hline Linfocitos & 0,92 & 1,44 & 1,77 & 2,2 & 2,57 & $1,5-4 \mathrm{mil} / \mathrm{mm}^{3}$ \\
\hline Hematocrito & 40,1 & 42 & 41,1 & 42 & 44 & $37-48 \%$ \\
\hline VCM & 86 & 88 & 90 & 90 & 87,5 & $86-98$ micromm $^{3}$ \\
\hline Creatinina & 1,30 & 0,99 & 0,95 & 0,97 & 0,95 & $0,6-1,3 \mathrm{mg} / \mathrm{dl}$ \\
\hline Potasio & 3,39 & 4,06 & 4.3 & 4,2 & 4,1 & $3,5-5,5 \mathrm{mEq} / \mathrm{L}$ \\
\hline Sodio & 146 & 155 & 136 & 140 & 138 & $135-145 \mathrm{mEq} / \mathrm{L}$ \\
\hline Cloro & 108 & & & & & $95-110 \mathrm{mEq} / \mathrm{L}$ \\
\hline Calcio & 8,29 & & & & & $8.5-10,5 \mathrm{mg} / \mathrm{dl}$ \\
\hline PCR & 92 & 43,95 & 22,9 & $<5$ & $<5$ & $<5 \mathrm{mg} / \mathrm{L}$ \\
\hline TGP & & 22 & 18 & 25 & 25 & 10-50UI/L \\
\hline
\end{tabular}

Convenciones. VCM: volumen corpuscular medio; PCR: proteína C reactiva; LDH: deshidrogenasa láctica; TGO: transaminasa glutámica oxalacética; TGP: transaminasa glutámico pirúvica 
Se le administró desde el primer día de su ingreso ivermectina 135 gotas (3 gotas $/ \mathrm{kg} /$ dosis $\mathrm{VO}$ al ingreso, a los 8 y a los 15 días), nitazoxanida (500 mg VO cada 12 horas por 8 días), dexametasona ( $8 \mathrm{mg}$ IV cada día por 10 días) acudida por la desaturación y necesidad de oxígeno suplementario de la paciente, ASA (100 mg VO cada día), terapia respiratoria, física y ocupacional. Por dímero $\mathrm{D}>1500$ se decidió inicio de enoxaparina a dosis de anticoagulación, atorvastatina (20 mg cada día) y reposición oral de potasio.

En la Figura 1 se presenta la evolución de constantes vitales durante su hospitalización y en la Figura 2, la evolución de paraclínicos, después de haber iniciado el manejo, donde se observa mejoría progresiva de saturación de oxígeno, de cifras tensionales y disminución de reactantes de fase aguda, respectivamente. A los 16 días de haber iniciado la sintomatología se toman pruebas rápidas IgG e IgM para coronavirus, resultando positivas.

A los 18 días de haber iniciado el manejo, se observa paciente con buen estado general y mejoría de su mecánica ventilatoria, sin requerimiento de oxígeno suplementario en los últimos 3 días, estable hemodinámicamente, alerta, tolerando adecuadamente la vía oral, movilizándose dentro de sus limitaciones funcionales de base. Además, descenso de marcadores de respuesta inflamatoria con negativización de PCR, por lo que se consideró caso recuperado, y se consideró alta hospitalaria.

En la Tabla 2 se presenta la secuencia de eventos importantes durante la evolución hospitalaria de la paciente.

\section{Consideraciones éticas}

Se contó con el consentimiento informado de parte del familiar de la paciente y las precauciones necesarias para garantizar la privacidad de esta (protección de los datos con base anonimizada y manejo de estos por el equipo investigador). El estudio fue aprobado por el Comité de Ética y Científico del Hospital Geriátrico y Ancianato San Miguel, con número de referencia 1.16.1.030.2021.

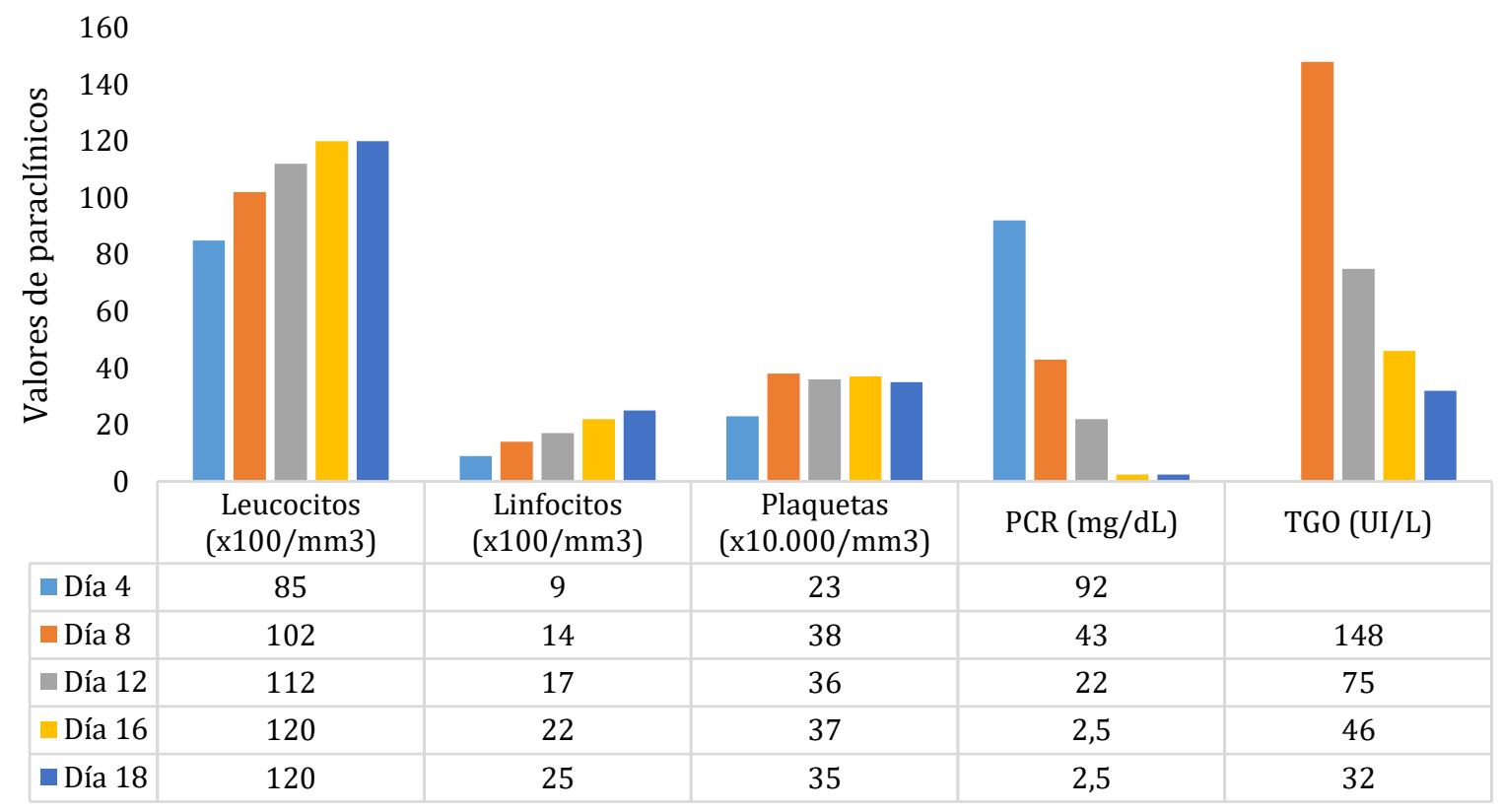

Tipo de paraclínico

- Día 4 Día 8 Día 12 Día 16 Día 18

Figura 2. Evolución paraclínicos de la paciente durante la hospitalización. * Día 3: administración de primera dosis ivermectina, nitazoxanida, dexametasona, ASA, atorvastatina, enoxaparina profiláctica, terapia respiratoria, física y ocupacional 
Tabla 2. Línea de tiempo de sucesos importantes durante la hospitalización de la paciente

\begin{tabular}{|c|c|}
\hline Día & Sucesos importantes de la clínica de la paciente \\
\hline Día 0 & Día de inicio de los síntomas \\
\hline Día 3 & Consulta a UGA e inicio de tratamiento médico \\
\hline Día 7 & $\begin{array}{l}\text { Disminución de reactantes de fase aguda e inicio de } \\
\text { mejoría de mecánica ventilatoria }\end{array}$ \\
\hline Día 8 & $\begin{array}{l}\text { Disminuyó la necesidad de concentración de oxígeno } \\
\text { suplementario y continúa mejoría de mecánica } \\
\text { ventilatoria y cifras tensionales }\end{array}$ \\
\hline Día 16 & $\begin{array}{l}\text { Suspensión de oxígeno suplementario y prueba } \\
\text { rápida Ac IgG e IgM positivas para COVID-19 }\end{array}$ \\
\hline Día 18 & Alta hospitalaria \\
\hline
\end{tabular}

\section{Discusión}

Se presentó el caso clínico de una AM centenaria paciente frágil con COVID-19 (diagnosticada con prueba RT-PCR para SARS-CoV-2), con multimorbilidad, en contexto de brote de COVID-19 a nivel de la institución geriátrica en la cual residía, con NEWS y CALL score muy elevados, con criterios de severidad, alto riesgo de progresión, pobre pronóstico (Tabla 1 y Figura 1), riesgo de mortalidad elevado, con necesidad de oxígeno suplementario a altas concentraciones. Se diagnosticó y se inició manejo de manera precoz con desenlace clínico y paraclínico favorable.

Se ha informado que la edad es un predictor de mal pronóstico en pacientes con COVID-19(1-4); además se conoce que hasta un $27 \%$ de los pacientes mayores de 65 años llegan al servicio de urgencias con enfermedad grave(7), como es el caso de la paciente que desde su ingreso mostraba criterios de severidad de la enfermedad. En estudios recientes se ha determinado que la desaturación $\left(\mathrm{SaO}^{2}<90 \%\right)$, taquicardia (>100 LPM), taquipnea y alteración del estado de conciencia se comportan como factores independientes de riesgo de mortalidad en pacientes AM, así como el antecedente de hipertensión arterial(16), condiciones con las cuales contaba la paciente del caso.

Dentro de los paraclínicos solicitados a la paciente al ingreso, se identificó linfopenia severa y elevación marcada de PCR, ferritina, dímero D y LDH. En el estudio de Hewitt et al.,(16) estos factores de igual manera se comportaron como predictores de mortalidad en pacientes AM. Un criterio adicional al pronóstico ominoso de la paciente fue la presencia de fragilidad evaluada, en este caso mediante la escala clínica de fragilidad, siendo una medida subrogada de la edad biológica; en efecto estudios previos han documentado la relación entre fragilidad y mortalidad en los pacientes con COVID-19, incluso después de evaluar la edad cronológica y otras condiciones crónicas de salud presentes(16).

Los pacientes AM con multimorbilidad tienen más probabilidad de progresar a enfermedad grave(10). El envejecimiento se acompaña de procesos fisiológicos como la inmunosenescencia, que dificulta el reconocimiento y eliminación de patógenos y por otro lado hay una exagerada respuesta inflamatoria sistémica pero ineficaz para eliminar el microorganismo en cuestión, lo que se traduce en una mayor gravedad de la enfermedad infecciosa(10,13).

Ante signos de severidad de la enfermedad del caso clínico y teniendo en cuenta la susceptibilidad inmunológica conferida a su edad, se decidió iniciar manejo médico de carácter temprano (a su ingreso). Con respecto al manejo clínico de COVID-19 éste debe ser guiado por la Organización Mundial de la Salud (OMS) y los Centros para el Control y la Prevención de Enfermedades(17) y no existe una recomendación específica para los AM(18). Para los casos graves, el tratamiento debe incluir cuidados para apoyar las funciones de los órganos vitales(17). Estas medidas deben adaptarse a la multimorbilidad, polifarmacia y la fragilidad de los $\mathrm{AM}(17,19)$. Dado que estos pacientes experimentan un mayor número y gravedad de enfermedades crónicas y discapacidades, así como la disfunción inmunológica(20), en consecuencia el COVID-19 afectará de manera desproporcionada a esta población.

Un brote de COVID-19 en un hogar geriátrico en el área de Seattle, Washington, se asoció con mortalidad aproximada del $35 \%$ de AM y los informes más recientes destacan la infección en muchos otros centros de atención geriátricos(21), subrayando el riesgo de COVID-19 en esta población susceptible. La paciente del caso clínico es producto de un brote de la enfermedad en una residencia geriátrica, lo que activó la alarma por los antecedentes de alta mortalidad en esta población en estudios anteriores(22).

La multimorbilidad, definida como la coocurrencia de dos o más condiciones crónicas(23), y la polifarmacia, el uso de cinco o más medicamentos, son altamente prevalentes en $\mathrm{AM}^{(24)}$. Lograr un uso óptimo de la medicación en esta población es complejo y desafiante en circunstancias normales. Dado el efecto 
devastador de COVID-19 en los AM, particularmente aquellos con multimorbilidad, este desafío sólo aumenta. Si bien no existe un tratamiento antiviral específico para COVID-19, la OMS ha priorizado algunos medicamentos para ser investigados en ensayos clínicos basados en la efectividad clínica in vitro y los datos de seguridad disponibles(19). Se decidió de manera interdisciplinar en la UGA administrar desde su ingreso ivermectina, nitazoxanida, dexametasona, atorvastatina, terapia respiratoria, física y ocupacional.

Un panel de discusión crítico llegó a la conclusión que la ivermectina puede ser una molécula potencial para la profilaxis y el tratamiento de personas infectadas por coronavirus, debido a sus propiedades antivirales (inhibiendo selectivamente la proteína transportadora de importina $\alpha / \beta$ del huésped), lo que disminuye la translocación de la proteína de la nucleocápside del virus SARS-CoV-2) junto con su bajo costo, disponibilidad, tolerabilidad $\mathrm{y}$ seguridad(25). Este fármaco tiene potencial para convertir la RT-PCR negativa con rapidez, especialmente en la fase virémica temprana(26), razón por la cual se decidió utilizarlo una vez diagnosticada la enfermedad en el contexto del brote en la institución geriátrica. Esta puede considerarse como una opción terapéutica segura para casos leves, moderados o graves de COVID-19(25), no siendo ajenos a la necesidad urgente de un ensayo clínico aleatorio con adecuado diseño para el tratamiento de COVID-19.

Los estudios clínicos de ivermectina no incluyeron un número suficiente de sujetos de 65 años o más para determinar si responden de manera diferente a los sujetos más jóvenes. Otra experiencia clínica informada no ha identificado diferencias en las respuestas entre los pacientes AM y los más jóvenes(27). La paciente recibió una dosis de 200 $\mathrm{mcg} / \mathrm{Kg}$ al ingreso, a los 8 y a los 15 días.

Otra medicación importante utilizada en la paciente, fue la dexametasona que según el estudio RECOVERY resultó con una menor mortalidad a los 28 días entre los que estaban recibiendo ventilación mecánica invasiva o necesidad de oxígeno suplementario, con una aceptable participación de pacientes AM (con más de $40 \%$ mayores de 70 años)(28). En un metaanálisis prospectivo de ensayos clínicos de pacientes críticamente enfermos con COVID-19, la administración de corticosteroides sistémicos, en comparación con la atención habitual o placebo, se asoció con una menor mortalidad por todas las causas a los 28 días(29). La paciente desde su ingreso se encontraba desaturada y con necesidad de oxígeno en altas concentraciones por lo cual se decidió incluir la dexametasona dentro del tratamiento.

En cuanto a la nitazoxanida recientemente, estudios de laboratorio han sugerido su papel como agente antivírico de amplio espectro, que interfiere con la morfogénesis viral en el rotavirus( ${ }^{(30)}$. También puede limitar la entrada de virus, la liberación viral y la transmisión de célula a célula. Asimismo, interferir con las vías reguladas por el huésped y puede inhibir/suprimir la producción de citocinas proinflamatorias, incluidas Interleucina 6 (IL-6) y Factor de necrosis tumoral alfa (TNF $\alpha)^{(31,32)}$. Se ha demostrado que la nitazoxanida inhibe el SARS-CoV2 en estudios in vitro(33). No hay evidencia clara que pueda ser útil en el entorno clínico. En general, se tolera bien y los efectos secundarios son escasos( ${ }^{(34)}$.

Con respecto a las estatinas, éstas son inhibidoras de la proteína de respuesta primaria de diferenciación mieloide (MYD) 88 impidiendo inflamación abrumadora en el contexto de la enfermedad(35), además regulan el alza experimentalmente de la expresión del receptor ACE2 protegiendo contra la lesión pulmonar inducida por coronavirus(36) y disminución de la producción de interleucina 18 proinflamatoria (IL-18)(37). Un metaanálisis determinó un riesgo significativamente reducido de enfermedad mortal o grave con el uso de estatinas (HR agrupado =0,70; IC del 95\%: 0,53 - 0,94) en comparación con el no uso de estatinas en pacientes con COVID-19(35). Queda mucho por determinar sobre el régimen de estatinas para el tratamiento de COVID19 , aunque la evidencia disponible sugiere que la terapia con estatinas de intensidad moderada a alta podría ser efectiva(35). Se necesitan ensayos controlados aleatorios bien diseñados en el futuro para confirmar los beneficios de las estatinas en pacientes con COVID-19.

En las gráficas 1 y 2 se muestra la evolución de constantes vitales y de paraclínicos durante la hospitalización desde su ingreso, tras el pobre pronóstico y gran riesgo de progresión de la enfermedad al ingreso de la paciente, se le realizó valoración geriátrica integral y manejo con equipo interdisciplinario a nivel de una UGA, con instauración del manejo médico temprano, indicando mejoría de la cada una de las constantes vitales principales a través de los días de su hospitalización, 
como fueron las cifras tensionales, frecuencia respiratoria, saturación de oxígeno, disminución de reactantes de fase aguda con aumento progresivo de recuento de linfocitos, lo que podría indicar el potencial antinflamatorio del manejo, la reducción de progresión de enfermedad en una paciente con CALL score de 13 puntos y más que todo la generación de anticuerpos de tipo IgG e IgM teniendo en cuenta la dificultad para desarrollarlos en $\operatorname{AM}(10,12)$. Se resalta la importancia del manejo de la paciente a nivel de la UGA por un equipo interdisciplinario y una valoración geriátrica integral.

La correlación entre la seropositividad de anticuerpos y la protección contra la reinfección, así como en los desenlaces y evolución de la enfermedad y la presencia de comorbilidades en la población geriátrica, queda aún por dilucidar(38). Se podría atribuir que la paciente desarrolló anticuerpos debido a la severidad de la infección desde su ingreso, o a que el efecto antinflamatorio de las medicaciones administradas de manera temprana permitió que su sistema inmune se prepare de una manera adecuada para combatir la infección. Hoy en día es un caso recuperado de una centenaria con multimorbilidad y fragilidad, con enfermedad por la COVID-19 categorizada con criterios de severidad, quien desarrolló inmunidad frente a la infección.

La limitación más importante de este estudio, es que no es posible generalizar los resultados del manejo instaurado por su naturaleza de reporte de caso, sin embargo, hace parte de una base para construcción de hipótesis y posteriores ensayos clínicos aleatorizados que en un futuro permitan esclarecer su beneficio en términos de eficacia. De igual forma, serviría como base para casos clínicos similares en una entidad donde la evidencia y la literatura son escasas y poco concluyentes.

\section{Conclusiones}

El éxito del tratamiento de la COVID-19 y la generación de inmunidad en adultos mayores frágiles, con multimorbilidad y alto riesgo de progresión de enfermedad como la paciente del caso clínico, se centra en la activación precoz de una ruta protocolizada de atención institucional, incluyendo un diagnóstico temprano, valoración geriátrica integral, manejo interdisciplinario con tratamiento oportuno y un seguimiento estricto clínico y paraclínico para evitar desenlaces poco favorables y reducir al máximo el número de complicaciones.
Conflicto de intereses: Ninguno declarado por los autores.

\section{Referencias}

1. Yang W, Cao Q, Qin L, Wang X, Cheng Z, Pan A, et al. Clinical characteristics and imaging manifestations of the 2019 novel coronavirus disease (COVID-19): A multi-center study in Wenzhou city, Zhejiang, China. J Infect. 2020;80(4):388-93. DOI: 10.1016/j.jinf.2020.02.016.

2. Sun P, Lu X, Xu C, Sun W, Pan B. Understanding of COVID-19 based on current evidence. J Med Virol. 2020;92(6):548-51. DOI: $10.1002 /$ jmv.25722.

3. Onder G, Rezza G, Brusaferro S. Case-Fatality Rate and Characteristics of Patients Dying in Relation to COVID-19 in Italy. JAMA - J Am Med Assoc. 2020;323(18):1775-6. DOI: 10.1001/jama.2020.4683.

4. Wang W, Tang J, Wei F. Updated understanding of the outbreak of 2019 novel coronavirus (2019-nCoV) in Wuhan, China. J Med Virol. 2020;92(4):441-7. DOI: 10.1002/jmv.25689.

5. Coronavirus.jhu.edu. Coronavirus Resource Center resource center. Citado 2021 Jul 3. Disponible en: https://coronavirus.jhu.edu/

6. WHO.int. Coronavirus Disease (COVID-19) Situation Reports. Citado 2021 Jul 3. Disponible en https://www.who.int/emergencies/diseases/novelcoronavirus-2019/situation-reports

7. Guan W-J, Ni Z-Y, Hu Y, Liang W-H, Ou C-Q, He J-X, et al. Clinical Characteristics of Coronavirus Disease 2019 in China. $N$ Engl J Med. 2020;382(18):1708-20. DOI: 10.1056/NEJMoa2002032.

8. The OpenSAFELY Collaborative, Williamson E, Walker AJ, Bhaskaran K, Bacon S, Bates C, et al. OpenSAFELY: factors associated with COVID-19-related hospital death in the linked electronic health records of 17 million adult NHS patients. medRxiv. 2020 [citado en: 21 Sep 2020]. DOI: 10.1101/2020.05.06.20092999.

9. Santesmasses D, Castro JP, Zenin A, Shindyapina A, Gerashchenko M, Zhang B, et al. COVID-19 is an emergent disease of aging. medRxiv. 2020. DOI: 10.1101/2020.04.15.20060095.

10. Mueller AL, McNamara MS, Sinclair DA. Why does COVID-19 disproportionately affect older people? Aging. 2020;12(10):9959-81. DOI: 10.18632/aging.103344.

11. Franceschi $C$, Bonafè $M$, Valensin $S$, Olivieri $F$, De Luca $M$, Ottaviani E, et al. Inflamm-aging. An evolutionary perspective on immunosenescence. Annals of the New York Academy of Sciences. 2000;908(1):244-54. DOI: 10.1111/j.1749-6632.2000.tb06651.x.

12. Ongrádi J, Kövesdi V. Factors that may impact on immunosenescence: An appraisal. Immun Ageing. 2010;7(1):7. DOI: 10.1186/1742-4933-7-7.

13. Ocampo M. Estrés y enfermedades del adulto mayor. In: Herrera JA. Psiconeuroinmunología para la práctica clínica. $1^{a}$ ed. Santiago de Cali: Programa editorial Universidad del Valle; 2009. Capítulo 11. p. 109-128. Disponible en: https://bibliotecadigital.univalle.edu.co/bitstream/handle/ 10893/10384/Psiconeuroinmunologia.pdf?sequence=5

14. Smith SM, Wallace E, O'Dowd T, Fortin M. Interventions for improving outcomes in patients with multimorbidity in primary care and community settings. Cochrane Database 
Syst Rev. 2016;2016(3).

DOI: 10.1002/14651858.CD006560.pub3.

15. Guo T, Shen Q, Guo W, He W, Li J, Zhang Y, et al. Clinical Characteristics of Elderly Patients with COVID-19 in Hunan Province, China: A Multicenter, Retrospective Study. Gerontology. 2020;66(5):467-75. DOI: 10.1159/000508734.

16. Hewitt J, Carter B, Vilches-Moraga A, Quinn TJ, Braude P, Verduri A, et al. The effect of frailty on survival in patients with COVID-19 (COPE): a multicentre, European, observational cohort study. Lancet Public Heal. 2020;5(8):e444-51. DOI: 10.1016/S2468-2667(20)30146-8.

17. CDC.gov. Coronavirus Disease 2019 (COVID-19). Citado 2020 Sep $3 . \quad$ Disponible en: https://www.cdc.gov/coronavirus/2019-ncov/index.html

18. Garnier-Crussard A, Forestier E, Gilbert T, Krolak-Salmon P. Novel Coronavirus (COVID-19) Epidemic: What Are the Risks for Older Patients? J Am Geriatr Soc. 2020;68(5):939-40. DOI: 10.1111/jgs.16407.

19. WHO.int. Clinical management of COVID-19. Citado 2020 Sep 29. Disponible

en:

https://www.who.int/publications/i/item/clinical-

management-of-covid-19

20. Bandaranayake T, Shaw AC. Host Resistance and Immune Aging. Clin Geriatr Med. 2016;32(3):415-32. DOI: 10.1016/j.cger.2016.02.007.

21. WSJ.com. Coronavirus Outbreaks Spreading in Nursing Homes. Citado 2020 Sep 30. Disponible en: https://www.wsj.com/articles/coronavirus-outbreaksspreading-in-nursing-homes-11584628291

22. Bernal Torres W, Pérez Marmolejo DA, Gómez Gonzales B, Castro-Flóres X, Aristizabal-Gómez L, Ocampo Chaparro JM, et al. Ruta de manejo del adulto mayor con sospecha de infección por SARS CoV-2/COVID-19 en centros de protección de larga estancia para dultos mayores en el departamento del Valle del Cauca - Colombia. Rev ACGG. 2020;34(1):51-66. Disponible en: https://acgg.org.co/wpcontent/uploads/Art4_Revista_Gerontologia_Vol34_Final.pd $\mathrm{f}$

23. Marengoni A, Angleman S, Melis R, Mangialasche F, Karp A, Garmen A, et al. Aging with multimorbidity: A systematic review of the literature. Ageing Res Rev. 2011;10(4):430-9. DOI: 10.1016/j.arr.2011.03.003.

24. 2019 American Geriatrics Society Beers Criteria ${ }^{\circledR}$ Update Expert Panel. American Geriatrics Society 2019 Updated AGS Beers Criteria ${ }^{\circledR}$ for Potentially Inappropriate Medication Use in Older Adults. J Am Geriatr Soc. 2019;67(4):674-94. DOI: $10.1111 /$ jgs.15767.

25. Vora A, Arora VK, Behera D, Tripathy S. White paper on Ivermectin as a potential therapy for COVID-19. Indian J Tuberc. 2020;67(3):448-51. DOI: 10.1016/j.ijtb.2020.07.031.

26. Caly L, Druce JD, Catton MG, Jans DA, Wagstaff KM. The FDAapproved drug ivermectin inhibits the replication of SARSCoV-2 in vitro. Antiviral Res. 2020;178:104787. DOI: 10.1016/j.antiviral.2020.104787.
27. www.accessdata.fda.gov. FDA-Approved Drugs. Citado 2020 Sep $30 . \quad$ Disponible en: https://www.accessdata.fda.gov/scripts/cder/daf/index.cf $\mathrm{m}$ ? event $=$ overview.process \&ApplNo $=050742$

28. Horby P, Lim WS, Emberson J, Mafham M, Bell J, Linsell L, et al. Effect of Dexamethasone in Hospitalized Patients with COVID-19-Preliminary Report. medRxiv. 2020. DOI: 10.1101/2020.06.22.20137273.

29. WHO Rapid Evidence Appraisal for COVID-19 Therapies (REACT) Working Group. Association between administration of systemic corticosteroids and mortality among critically ill patients with COVID-19: A meta-analysis. JAMA - J Am Med Assoc. 2020;324(13):1330-41. DOI: 10.1001/jama.2020.17023.

30. Rossignol J-F. Nitazoxanide: A first-in-class broad-spectrum antiviral agent. Antiviral Res. 2014;110:94-103. DOI: 10.1016/j.antiviral.2014.07.014.

31. Rossignol J-F. Nitazoxanide, a new drug candidate for the treatment of Midle East respiratory syndrome coronavirus. J Infect Public Health. 2016;9(3):227-30. DOI: 10.1016/j.jiph.2016.04.001.

32. Hong SK, Kim HJ, Song CS, Choi IS, Lee JB, Park SY. Nitazoxanide suppresses IL-6 production in LPS-stimulated mouse macrophages and TG-injected mice. Int Immunopharmacol. 2012;13(1):23-7. DOI: 10.1016/j.intimp.2012.03.002.

33. Wang M, Cao R, Zhang L, Yang X, Liu J, Xu M, et al. Remdesivir and chloroquine effectively inhibit the recently emerged novel coronavirus (2019-nCoV) in vitro. Cell Res. 2020;30(3):269-71. DOI: 10.1038/s41422-020-0282-0.

34. Fox LM, Saravolatz LD. Nitazoxanide: A new thiazolide antiparasitic agent. Clin Infect Dis. 2005;40(8):1173-80. DOI: $10.1086 / 428839$.

35. Kow CS, Hasan SS. Meta-analysis of Effect of Statins in Patients with COVID-19. Am J Cardiol. 2020;134:153-5. DOI: 10.1016/j.amjcard.2020.08.004.

36. Li Y-H, Wang Q-X, Zhou J-W, Chu X-M, Man Y-L, Liu P, et al. Effects of rosuvastatin on expression of angiotensinconverting enzyme 2 after vascular balloon injury in rats. J Geriatr Cardiol. 2013;10(2):151-8. Disponible en: https://pubmed.ncbi.nlm.nih.gov/23888175/

37. Rogers AJ, Guan J, Trtchounian A, Hunninghake GM, Kaimal $\mathrm{R}$, Desai M, et al. Association of Elevated Plasma Interleukin18 Level With Increased Mortality in a Clinical Trial of Statin Treatment for Acute Respiratory Distress Syndrome. Crit Care Med. 2019;47(8):1089-96. DOI: 10.1097/CCM.0000000000003816.

38. Huang A, Garcia-Carreras B, Hitchings M, Yang B, Katzelnick L, Rattigan S, et al. A systematic review of antibody mediated immunity to coronaviruses: antibody kinetics, correlates of protection, and association of antibody responses with severity of disease. medRxiv. 2020. DOI: 10.1101/2020.04.14.20065771. 